\title{
Spatial proximity and the risk of psychopathology after a terrorist attack
}

\author{
Charles DiMaggio ${ }^{a, b}$, Sandro Galea ${ }^{a, c}$, and Michael Emch ${ }^{d}$ \\ aDepartment of Epidemiology, Columbia University, Mailman School of Pubic Health, 722 West 168 \\ St, New York, NY, USA \\ ${ }^{b}$ Department of Anesthesiology, Columbia University, College of Physicians and Surgeons, New \\ York, NY, USA \\ ${ }^{\circ}$ Center for Social Epidemiology and Population Health, University of Michigan \\ dSchool of Public Health, Ann Arbor, MI, USA, Department of Geography, University of North \\ Carolina, Chapel Hill, NC, USA
}

\begin{abstract}
Previous studies concerned with the relation of proximity to the September 11, 2001 terrorist attacks and subsequent psychopathology have produced conflicting results. The goals of this analysis are to assess the appropriateness of using Bayesian hierarchical spatial techniques to answer the question of the role of proximity to a mass trauma as a risk factor for psychopathology. Using a set of individual-level Medicaid data for New York State, and controlling for age, gender, median household income and employment-related exposures, we applied Bayesian hierarchical modeling methods for spatially-aggregated data. We, we found that distance from the World Trade Center site in the post-attack time period was associated with increased risk of anxiety-related diagnoses. In the months following the attack, each two mile increment in distance closer to the World Trade Center site was associated with a seven percent increase in anxiety-related diagnoses in the population. No similar association was found during a similar time period in the year prior to the attacks. We conclude that spatial variables help more fully describe post-terrorism psychiatric risk and may help explain discrepancies in the existing literature about these attacks. These methods hold promise for the characterization of disease risk where spatial patterning of ecologic-level exposures and outcomes merits consideration.
\end{abstract}

\section{Keywords}

epidemiology; disasters; terrorism; anxiety; Bayes Theorem; spatial analysis

\section{INTRODUCTION}

During the past decade there has been an increasing appreciation of the role of place in determining health (Sampson et al., 1997; Schwartz, 1994). Although the vast majority of research in this area has been concerned with physical health (Pickett and Pearl, 2001), there

\footnotetext{
() 2012 Elsevier Ireland Ltd. All rights reserved.

Correspondence to: Charles DiMaggio.

Publisher's Disclaimer: This is a PDF file of an unedited manuscript that has been accepted for publication. As a service to our customers we are providing this early version of the manuscript. The manuscript will undergo copyediting, typesetting, and review of the resulting proof before it is published in its final citable form. Please note that during the production process errors may be discovered which could affect the content, and all legal disclaimers that apply to the journal pertain.
} 
is growing appreciation of the importance of considering the relation between place and mental illness. Recent papers have shown, for example, (Galea et al., 2007; Weich et al., 2002) that persons living in areas characterized by less desirable built environments or by lower incomes are more likely to report depressive symptoms, independent of individual characteristics. As exemplified by these studies, most epidemiologic studies that have considered the role of determinants beyond individual risk and behavior have considered data that characterizes an individual's environment - typically data that are aggregated to administrative and political units such as ZIP codes and counties.

However, analyses that consider the role of aggregate group-level variables face challenges (Diez Roux, 2002; Galea and Ahern, 2006; O'Campo, 2003). Considering the role of aggregate variables frequently relies on heterogeneous and arbitrary groupings that may be too large and undifferentiated to capture risk appropriately, (Galea et al., 2005) Analyses that rely on variable specification based on irregular geographic units, such as ZIP codes, (Thomas et al., 2006) may be affected by extreme values based on few cases in small populations. (Devine et al., 1994) These rare events contribute to more heterogeneity than is assumed by commonly used epidemiological models. There may also be unacceptably high rates of address misspecification within the ZIP-code polygons. (Grubesic and Matisziw, 2006) Additionally, influential covariates of an outcome, which may be unmeasured, are likely to be similar in adjacent areas resulting in spatial autocorrelation and inflated risk estimates.

Bayesian methods may be uniquely suited to addressing these difficulties. They are well-suited to hierarchical approaches and allow the incorporation of results from neighboring spatial tracts to informatively smooth estimates. (Banerjee et al., 2004; Lawson et al., 2003) Bayesian models can accommodate unobserved or missing variables, and the use of information from prior studies (or lack thereof) is explicit and straightforward in a Bayesian approach. (Dunson, 2001)

In a Bayesian approach, our two main sources of information about parameters of interest $(\theta)$ are our prior beliefs or the prior distribution of the parameter $(\operatorname{Pr}[\theta])$ and the likelihood of observing the data given the parameter $(\operatorname{Pr}[\mathrm{y} \mid \theta])$. Our prior distribution indicates how we believe the parameter would behave if we had no data upon which to base our judgments. The likelihood informs about $\theta$ via the data itself. When we have a lot of data, the likelihood predominates, and our results will essentially be the maximum likelihood estimate. When we have less data, the prior has greater influence.(Greenland, 2006; Lawson et al., 2003) The result of combining the prior distribution and the likelihood is called the posterior distribution and follows Bayes' Theorem:

$$
\operatorname{Pr}[\theta \mid \mathrm{y}] \alpha \operatorname{Pr}[\mathrm{y} \mid \theta] * \operatorname{Pr}[\theta]
$$

In a hierarchical (or mixed) Bayesian model we specify not only a distribution for how we believe risk $(\theta)$ is distributed across a group of individuals, but also how we believe $\theta$ varies across higher levels of organization, such as geographic units, by specifying an additional set of parameters $(\lambda)$. One could, for example, say that $\mathrm{y}_{i}$ is the empirical (observed) rate of some event in a geographic area $i, \theta$ is the true underlying rate, and $\lambda$ how that true rate varies across all such areas in which we are interested.(Banerjee et al., 2004) Such specifications can help account for irregular groupings, autocorrelation and the effects of extreme values.

While spatial analysis is common in the environmental and infectious disease literature (Mirabelli et al., 2006; Sarkar et al., 2002) and proximity to environmental hazards has long been known to determine a number of health outcomes (Ala et al., 2006; Bithell, 1995; Diggle and Rowlinson, 1994; Emch, 1999; Michelozzi et al., 2002; Viel et al., 2000; Waller et al., 
1992) it is employed less often in other areas of epidemiology such as in mental and behavioral health. It is the purpose of this manuscript to demonstrate the applicability of Bayesian hierarchical spatial modeling to a question of interest to psychiatric epidemiology. Specifically, we focus here on the relation between spatial proximity to traumatic event exposure and subsequent psychopathology.

A substantial and growing body of evidence has demonstrated psychopathology after the terrorist attacks of September 11, 2001 (Chen et al., 2003; DiMaggio et al., 2006; Galea et al., 2002a; Galea et al., 2002b), but research on the role of residential proximity to the site of the attack on subsequent mental health pathology is divided. Population-based reports have suggested post-traumatic stress disorder (PTSD) prevalence of 7.5\% in Manhattan residents in the first month following the attack(Galea et al., 2002a) and estimates as high as $20 \%$ to $50 \%$ for residents of neighborhoods in the immediate vicinity of the World Trade Center site (Galea et al., 2002b) (Chen et al., 2003). However, these findings conflict with reports that individuals with existing diagnoses of post-traumatic stress disorder did not exhibit significantly worse symptoms than in previous years (Rosenheck and Fontana, 2003b) In addition, evidence of increased health service utilization, (Boscarino et al., 2004; Fagan et al., 2003) and increased psychotropic drug use (Kettl and Bixler, 2002) (DiMaggio et al., 2006) after this event are contradicted by data that show there was no significant increase in the utilization of mental health services for the treatment of PTSD among military veteran's in the New York City area, (Rosenheck and Fontana, 2003a) and that any increase in anti-depressant use at the population level was small and not statistically significant.(McCarter and Goldman, 2002)

In this study we specify a hierarchical Bayesian model to examine the role of proximity to a terrorist event in determining mental health outcomes in a population of Medicaid enrollees by utilizing data on anxiety-related diagnoses in New York City following the terrorist attacks of September 11, 2001.

\section{METHODS}

We used data from Medicaid analytic extract files for New York State residents for 2000 and 2001.(CMS, 2006) These are a complete set of individual-level data files on all New York State residents who received Medicaid-funded inpatient, outpatient, and long-term care service. We restricted our analyses to outpatient services which included private practices, clinics and emergency department visits. We collected information on patient identifiers, demographics, ZIP code of residence, eligibility status by month, and primary international classification of diseases (ICD-9) diagnostic codes.(2004)

We compared the time periods of September $12^{\text {th }}, 2001$ to December 31 ${ }^{\text {st }}, 2001$ (the attack period) and September $12^{\text {th }} 2000$ to December $31^{\text {st }}, 2000$ (the control period), and restricted our analysis to Medicaid enrollees older than 8 years of age with ZIP codes of residence within New York City. Distance from the WTC site ranged from 2.2 miles to 20.5 miles. We based the designation of anxiety disorders on a set of diagnoses first proposed by the US Surgeon General's office.(Satcher, 2000) They consisted of the following ICD-9 codes: 300.20 (phobia) 300.21 (agoraphobia with panic) 300.22 (agoraphobia without panic) 300.23 ( social phobia) 300.29 (isolated phobias) 300.3 (obsessive-compulsive disorder) 300.00 (anxiety state) 300.01 (panic disorder) 300.02 (generalized anxiety disorder) 300.09 (anxiety state) 309.81 (prolonged post-traumatic stress) 309.24 (adjustment reaction-anxious mood).

To examine the effect of residential distance from the World Trade Center (WTC) site on outpatient anxiety-related diagnoses in New York City neighborhoods in the months following the terrorist attacks of September 11, 2001, we controlled for age, gender, terrorist-related deaths in communities, and median household income and drew inferences based on the 
statistical significance of model coefficients for the distance in miles of New York City ZIPcode tabulation areas from the WTC site, attack-related deaths per 10,000 population, 2000 census reports of median household income for age and gender controlled standardized morbidity ratios.

Because the only geographic identifier in the Medicaid data set was ZIP code of residence, point pattern analyses were not possible. Our outcome variables were age and gender standardized morbidity ratios (SMR) for anxiety-related ICD-9 diagnoses for each ZIP code tabulation area. We based expected rates on the internal standard of New York City as a whole for the relevant 3-month period and using a variable based on person-years of Medicaid eligibility to calculate the rates. Our exposure variable was the distance in miles from the World Trade Center site using the latitude and longitude of the ZIP code centroids in radians and the Great Circle Distance Formula.(SAS, 2006) We used the number of September 11, 2001 terrorist attack deaths per 10,000 population in a ZIP code as a proxy control for employment exposure to the WTC site during the terrorist attack. Age and gender were included in the SMR, and we controlled for socio-economic status with median household income. To improve convergence to the posterior distribution, the distance and median household income variables were standardized and we used the natural $\log$ of the death rate.

Hierarchical Bayesian spatial models describe observed cases in a geographic unit as Poisson distributed with a mean equal to the expected number of cases $\left(\mathrm{E}_{i}\right)$ times the risk $\left(\rho_{i}\right)$ for that area: (Richardson et al., 2006)

$$
\mathrm{O}_{i} \sim \text { Poisson }\left(\rho_{i} \mathrm{E}_{i}\right)
$$

In describing the likelihood, the risk for each area $(\rho)$ is transformed to a log scale (making relationships additive rather than multiplicative) and is set equal to an intercept term (a) and two random effects, one non-spatial $(\theta)$ the other spatial $(\lambda)$ :

$$
\log \rho_{i}=\mathrm{a}+\theta_{i}+\lambda_{i}
$$

The spatially structured component is described as a conditional autoregressive (CAR) Gaussian process $\left(\lambda \sim \operatorname{CAR} \operatorname{Normal}\left(\mathrm{W}, \tau_{\lambda}\right)\right)$ where the conditional distribution of each $\lambda_{i}$, given all the other $\lambda_{i}$ 's, is normal with $\mu=$ the average $\lambda$ of its neighbors and a precision $\left(\tau_{\lambda}\right)$ proportional to the number of neighbors. W represents the matrix of neighbors that defines the neighborhood structure. The simplest and most commonly used definition of a set of neighboring structures is the existence of a common border between areas. (Congdon, 1997; Congdon, 2001; Curtis et al., 2006; da Silva et al., 2004; Waller et al., 1997) The non-spatial component of the model $\left(\theta_{i}\right)$ is defined at normally distributed with $\mu=0$ and precision $\left(\tau_{\theta}\right)$. The model is completed by assigning additional (hyperprior) distributions to the precision terms $\tau_{\lambda}$ and $\tau_{\theta}$

The approach most frequently described in the mapping literature is the Poisson-gamma model. In this formulation the risk $(\theta)$ is described as a set of parameters that may include any number of explanatory variables. (Lawson et al., 2003) The prior distribution of the observed outcome $\mathrm{y}$ is described as $\mathrm{y} \mid \theta \sim \operatorname{Po}(\theta \mathrm{E})$ and the hyper-prior distribution of the risk is $\theta \mid \alpha, \beta \sim$ Gamma $(\alpha, \beta)$, with $\mu=\alpha / \beta$ and $\sigma^{2}=\alpha / \beta^{2}$. (Banerjee et al., 2004; Lawson et al., 2003) We could further specify $\alpha$ and $\beta$, but we assume that beyond a certain point further model specification will have little practical effect on our results. We commonly choose a non-informative (proper) or arbitrarily vague prior that is uniform or "flat" to allow the data to predominate and lead us to 
a posterior distribution that is dominated by the likelihood. A Gamma $(0.5,0.0005)$ has been suggested as reasonable.(Law J and $\mathrm{R}, 2004)$

For simple models for which there is a closed form (i.e. they behave as true distributions and integrate to 1) we can estimate the posterior distribution directly via the maximum likelihood estimate. But most reasonably realistic models require sample-based approaches.

We entered our data into a Poisson-gamma model (explained above) first described by Clayton and Kaldor(Clayton and Kaldor, 1987) and expanded by Banerjee, Carlin and Gelfand.

(Banerjee et al., 2004) Our full model, then, consisted of the dependent variable as the log of the observed count of anxiety diagnoses with three explanatory covariates, $\beta_{1} \times$ a standardized distance in miles from the World Trade Center site, $\beta_{2} \times$ natural log of the ZIP code tabulation area September 11, 2001 death rate per 10,000, and $\beta_{3} \times$ standardized median household income for the ZIP code tabulation area. We compared this fitted, spatially smoothed, SMR calculations to the unfitted SMR calculations. ${ }^{1}$

We prepared the data and conducted descriptive and demographic analyses in SAS version 9.1. (2006) We used WinBUGS software(Baca Baldomero et al., 2004) to run 3 parallel Monte Carlo Markov Chains with over-dispersed initial values for 120,000 iterations. The first 60,000 iterations were discarded as a burn-in, and our inferences were based on the second 60,000 iterations. We assessed convergence by examining trace histories for parallel chains, and we used R software(205) to conduct the Brooks, Gelman and Rubin and the Geweke convergence diagnostics as well as the Heidleberger and Welch stationarity test. We present our results as median values for the coefficients with their associated $95 \%$ equal-tailed Bayesian confidence intervals as well as their kernel density graphs. We present maps of ZIP code tabulation areas comparing smoothed SMR estimates for 2000 and 2001.

The study was approved by the Columbia University institutional review board with protocol designation AAAB0209. 


\section{RESULTS}

There were 11,298,266 outpatient Medicaid visits between September $12^{\text {th }}$ and December $31^{\text {st }}, 2001 ; 6,302,508(55.8 \%)$ involved females and 4,882,618 (43.2\%) males; the average age was 38 years. Of these visits, 123,698 (1.1\%) involved an anxiety-related primary diagnosis; $76,987(62.2 \%)$ involved females, 46,704 (37.8\%) involved males and the average age was 41 years.

Between September $12^{\text {th }}$ and December $31^{\text {st }}, 2000$ there were 9,644,727 (14.6 percent fewer) outpatient Medicaid visits of which 5,454,118 (56.6\%) involved females and 4,111,834 $(42.6 \%)$ males with an overall average age of 38 years. Of these visits, 124,126 (1.3\%) involved a primary anxiety-related diagnosis. Among patients with anxiety-related diagnosis in the postSeptember $11^{\text {th }}, 2000$ time period 77,807 (62.7\%) involved females, 46,309 (37.3\%) involved males and the average age was 41 years.

We applied the full model to data from both time periods, running three chains with overdispersed initial values. Convergence following the 60,000 iteration burn-in period was acceptable. Brooks, Gellman and Rubin Potential Scale Reduction Factors for the three $\beta$ coefficients and the $\tau$ precision term were all 1.0. These same monitored nodes passed the Heidleberger and Welch Stationarity tests for all 3 chains. p values from the Geweke diagnostic were less than 0.03 for all nodes. Representative convergence tracings are presented in Figure 1 .

The distance of an individual's residence to the World Trade Center site in the post-September $11^{\text {th }}, 2001$ terrorist attack time period was the only statistically significant indicator of anxietyrelated diagnoses in a community. No other variable in either time period was a significant predictor of anxiety-related diagnoses (Table 1). The rate of terrorism-related deaths in a community was not associated with the number of anxiety-related diagnoses (Figure 2).

Holding all other model elements constant by inserting median values, each two mile increment toward the World Trade Center site resulted in approximately seven percent more anxietyrelated diagnoses. The absolute increases were greater the closer a community was to the WTC site. A community 28 miles away from the WTC site would have 24 additional anxiety-related diagnoses than a similar community 30 miles away. A community four miles from the WTC site could be expected to have 43 more anxiety-related diagnoses if it were two miles from the site (Figure 3).

When we mapped and compared 2000 and 2001 fitted SMR values for September $12^{\text {th }}$ to December $31^{\text {st }}$, it appeared that several ZIP code tabulation areas experienced increased anxiety-related diagnoses in the post-attack period (Figure 4). Notably, areas of Staten Island (one of the five boroughs of New York City) which contains large numbers of residences of first responders such as fire fighters, appeared to experience the most noticeable increases.

\section{DISCUSSION}

Our work demonstrates that the risk of anxiety disorders in the general population following exposure to a traumatic incident such as a terrorist attack is predicated in part on proximity to the event. Knowing that physical proximity of one's residence to a terrorist attack is significantly associated with risk of disease provides useful information for policy and public health response to such incidents.

Beyond the implications for preparedness, our study highlights the importance of considering neighborhood-level and spatial variables in psychiatric epidemiologic analysis, and the utility of hierarchical Bayesian approaches in this regard. Although there were intimations of the role 
proximity to this event played in determining the mental health consequences in its aftermath, with the highest prevalence proportions found among persons living closest to the World Trade Center site,(Chen et al., 2003) studies that considered the rates of mental health service utilization at different administrative units of aggregation failed to show an association between spatial location and use of mental health services after these attacks. (McCarter and Goldman, 2002; Rosenheck and Fontana, 2003a)

Considering space in psychiatric epidemiologic analysis is in many ways a throw back to an earlier era,(Brody et al., 2000) and is standard in environmental epidemiology, but it may deserve wider application. Physical location may be a missing component in many epidemiologic inquiries. We already routinely assess characteristics of persons (risk factors), and increasingly consider time (follow-up periods; life-course analyses), but far less routinely do we think about location. As psychiatric epidemiologic inquiry proceeds to better locate individuals within their full time-space lifetime continuum, and as we increasingly recognize the complex determination of disease, (Kuh et al., 2003; Susser, 2004; Wang, 2006) understanding the role of space becomes central in the full understanding of certain health outcomes.

The methods we present have much to offer, with some limitations. Full Bayes' methods base inferences on a sample of the full posterior distribution. The results from such a sample are not as informative as the closed form itself. We can increase the precision of our estimates by increasing the sample size. The sample itself is constructed through Markov Chain Monte Carlo methods and an important consideration is diagnosing convergence to the stationary posterior distribution. A commonly accepted approach is to run and dynamically monitor a number of parallel chains and examine the trace plots for when they start to overlap as an indication of convergence. We then throw out the burn-in period samples and base inference on the stationary Markov Chain. Statistics, such as the Gellman Rubin statistic, which compares variation within chains to those between chains for evidence of scale reduction, may be useful in diagnosing convergence. Other convergence statistics are based on examining individual chains.

Although using these methods to better understand the potential contribution of area of residence improves on what has been carried out thus far in considering the role of space, clearly area of residence does not fully capture the spatial risk of exposure. New York is a commuter city and many individuals who were exposed to the events of that day lived far from the WTC site. We attempted to control for this kind of exposure by using the terrorist-related death rate as a proxy measure of a community's non-residential spatial exposure, as well perhaps of community-level loss. We found a statistically significant effect for residence despite controlling for this additional exposure (which itself bordered on statistical significance) and despite the non-differential nature of this potential bias.

Our analysis is inherently ecologic and caution is required in making individual-level inferences. Ecological studies typically explain less variation than do individual-level studies. (Diez Roux, 2001; Macintyre et al., 1993; Mayer and Jencks, 1989) Also, due to the limited number of relevant explanatory variables in large administrative data sets, mapping studies such as ours could include unmeasured confounders, such as mental health service availability or social and family environment. An advantage of a Bayesian approach in this context is that modeling with random effects allows for unknown confounding. We assumed that the underlying parameters were not fixed (as in classical frequentist approach) but themselves varied and could be characterized by their hyper-parameters.

Medicaid is a federal, state, and in New York State, a locally funded health insurance program with locally determined income, age, and disability requirements. This vulnerable group differs from the general population in ways that affect their mental health and medical care utilization, 
(Salsberry et al., 2005). Despite this, the reliability of using Medicaid databases for analyzing mental health diagnoses(Walkup et al., 2000) has been validated

One may fairly ask why we chose to aggregate data rather than conduct individual-level analyses. The SMRs upon which the outcome of interest was based was calculated using individual-level data. Our primary interest though, the community-level role of distance from the event, was inherently ecologic. We also sought to demonstrate how the type of count data commonly available to applied epidemiologist could be analyzed to account for different levels of risk.

We would have preferred to conduct the analyses at a smaller, more uniform areal level such as census tracts but the data were not available. This is a position in which many epidemiologists may find themselves. Postal codes are administratively convenient but may be analytically unstable because the size of the population at risk may vary considerably and arbitrarily. Epidemiologically, they are far from ideal, and the argument can be made that finer geographical resolution could be accommodated within the confines of subject confidentiality. (Grubesic and Matisziw, 2006)

Spatial variability in postal codes may be more a reflection of the underlying, arbitrarily distributed population than of any true underlying disease process.(Richardson, 2003) We relied on hierarchical modeling to help address some of these issues of instability and overdispersion.(Lawson et al., 2003) In this way, we offer a spatial independent variable while considering the underlying spatial structure of the study area. Future studies could profitably address the issue of clusters of psychopathological outcomes by using such tools as the nearest neighbor index (ESRI, 2005), Ripley's K function (Levine, 2004), or a space-time permutation scan statistic (Kuldorf, 2005).

In conclusion, we present the example of anxiety-related diagnoses following the terrorist attacks of September 11, 2001 to illustrate one way in which spatial characteristic can be considered in psychiatric epidemiologic analyses. This approach may help explain discrepancies between competing analyses that have not accounted for location when it matters. The consideration of space and the application of appropriate methods to address its role, such as Bayesian hierarchical modeling, hold promise for psychiatric epidemiology and may contribute to the goal of fully characterizing the determinants of health in populations.

\section{Acknowledgments}

This work was funded by Centers for Disease Control and Prevention Health Protection Research Initiative Grant Number 1 K01 CE000494.

\section{References}

Ala A, Stanca CM, Bu-Ghanim M, Ahmado I, Branch AD, Schiano TD, Odin JA, Bach N. Increased prevalence of primary biliary cirrhosis near Superfund toxic waste sites. Hepatology. 2006; 43(3):52531. [PubMed: 16496326]

Baca Baldomero E, Cabanas Arrate ML, Perez-Rodriguez MM, Baca-Garcia E. Trastornos mentales en las victimas de atentados terroristas y sus familiares. Medicina Clinica. 2004; 122(18):681-5. [PubMed: 15171826]

Banerjee, S.; Carlin, BP.; Gelfand, AE., editors. Hierarchical modeling and analysis for spatial data. Chapman \& Hall/CRC; 2004.

Bithell JF. The choice of test for detecting raised disease risk near a point source. Statistical Medicine. 1995; 14(21-22):2309-22. 
Boscarino JA, Galea S, Adams RE, Ahern J, Resnick H, Vlahov D. Mental health service and medication use in New York City after the September 11, 2001, terrorist attack. Psychiatric Services. 2004; 55 (3):274-83. [PubMed: 15001728]

Brody H, Rip MR, Vinten-Johansen P, Paneth N, Rachman S. Map-making and myth-making in Broad Street: the London cholera epidemic, 1854. The Lancet. 2000; 356(9223):64-8.

Chen H, Chung H, Chen T, Fang L, Chen JP. The emotional distress in a community after the terrorist attack on the World Trade Center. Community Mental Health Journal. 2003; 39(2):157-65. [PubMed: 12723849]

Clayton D, Kaldor J. Empirical Bayes estimates of age-standardized relative risks for use in disease mapping. Biometrics. 1987; 43(3):671-81. [PubMed: 3663823]

CMS. Medicaid Analytic eXtract (MAX) General Information Vol 2006. Centers for Medicare and Medicaid Services; 2006.

Congdon P. Bayesian models for the spatial structure of rare health outcomes: a study of suicide using the BUGS program. Health \& Place. 1997; 3(4):229-247.

Congdon P. Bayesian models for suicide monitoring. European J Population. 2001; 15(3):1-34.

Curtis S, Copeland A, Fagg J, Congdon P, Almog M, Fitzpatrick J. The ecological relationship between deprivation, social isolation and rates of hospital admission for acute psychiatric care: a comparison of London and New York City. Health and Place. 2006; 12(1):19-37. [PubMed: 16243678]

da Silva, S.; Melo, L.; Ehlers, R. Spatial Analysis of Incidence Rates: A Bayesian Approach. Vol. 2006. 2004.

Devine OJ, Louis TA, Halloran ME. Empirical Bayes methods for stabilizing incidence rates before mapping. Epidemiology. 1994; 5(6):622-30. [PubMed: 7841244]

Diez, Roux AV. Investigating neighborhood and area effects on health. American Journal of Public Health. 2001; 91(11):1783-9. [PubMed: 11684601]

Diez Roux AV. Invited commentary: places, people, and health. American Journal of Epidemiology. 2002; 155(6):516-9. [PubMed: 11882525]

Diggle P, Rowlinson B. A conditional approach to point process modeling of elevated risk. Journal of the Royal Statistical Society. 1994; (157):433-440.

DiMaggio C, Galea S, Madrid P. Changes in Selective Serotonin Reuptake Inhibitor Prescription Rates Following a Terrorist Attack. Psychiatric Services. 2006; 57(11):1656-1657. [PubMed: 17085620]

Dunson DB. Commentary: practical advantages of Bayesian analysis of epidemiologic data. American Journal of Epidemiology. 2001; 153(12):1222-6. [PubMed: 11415958]

Emch M. Diarrheal disease risk in Matlab, Bangladesh. Social Science Medicine. 1999; 49(4):519-30. [PubMed: 10414811]

ESRI. ArcGIS. ESRI; 2005.

Fagan J, Galea S, Ahern J, Bonner S, Vlahov D. Relationship of self-reported asthma severity and urgent health care utilization to psychological sequelae of the September 11, 2001 terrorist attacks on the World Trade Center among New York City area residents. Psychosomatic Medicine. 2003; 65(6): 993-6. [PubMed: 14645777]

Galea S, Ahern J. Invited commentary: Considerations about specificity of associations, causal pathways, and heterogeneity in multilevel thinking. American Journal of Epidemiology. 2006; 163(12):1079_ 82. discussion 1083. [PubMed: 16707654]

Galea S, Ahern J, Nandi A, Tracy M, Beard J, Vlahov D. Urban neighborhood poverty and the incidence of depression in a population-based cohort study. Annals of Epidemiology. 2007; 17(3):171-9. [PubMed: 17320784]

Galea S, Ahern J, Resnick H, Kilpatrick D, Bucuvalas M, Gold J, Vlahov D. Psychological sequelae of the September 11 terrorist attacks in New York City. New England Journal of Medicine. 2002a; 346 (13):982-7. [PubMed: 11919308]

Galea S, Nandi A, Vlahov D. The Epidemiology of Post-Traumatic Stress Disorder after Disasters. Epidemiol Rev. 2005; 27(1):78-91. [PubMed: 15958429]

Galea S, Resnick H, Ahern J, Gold J, Bucuvalas M, Kilpatrick D, Stuber J, Vlahov D. Posttraumatic stress disorder in Manhattan, New York City, after the September 11th terrorist attacks. Journal of Urban Health. 2002b; 79(3):340-53. [PubMed: 12200503] 
Greenland S. Bayesian perspectives for epidemiological research: I. Foundations and basic methods. International Journal of Epidemiology. 2006; 35(3):765-75. [PubMed: 16446352]

Grubesic TH, Matisziw TC. On the use of ZIP codes and ZIP code tabulation areas (ZCTAs) for the spatial analysis of epidemiological data. International Journal of Health Geography. 2006; 5:58.

International classification of diseases, 9th revision, clinical modification: physician ICD-9-CM, 2005. AMA Press; 2004.

Kettl P, Bixler E. Changes in psychotropic drug use after September 11, 2001. Psychiatric Services. 2002; 53(11):1475-6. [PubMed: 12407280]

Kuh D, Ben-Shlomo Y, Lynch J, Hallqvist J, Power C. Life course epidemiology. J Epidemiol Community Health. 2003; 57(10):778-83. [PubMed: 14573579]

Kuldorf, M. SatScan: software for the spatial and space-time scan statistics. Information Management Services, Inc; 2005.

Law J, RH. A Bayesian approach to modeling binary data: the case of high intensity crime areas. Geographic Analysis. 2004; 36(3):197-216.

Lawson, A.; Browne, W.; Vidal Rodeiro, C. Disease Mapping with WinBUGS and MLWin. John Wiley and Sons Ltd; 2003.

Levine, N. CrimeStat: A Spatial Statistics Program for the Analysis of Crime Incident Locations. National Institute of Justice; 2004.

Macintyre S, Maciver S, Soomans A. Area, Class and Health: Should we be Focusing on Places or People? Journal of Social Policy. 1993; 22(2):213-234.

Mayer S, Jencks C. Growing Up in Poor Neighborhoods: How Much Does it Matter? Science. 1989; (243):1441-1445. [PubMed: 17839748]

McCarter L, Goldman W. Use of psychotropics in two employee groups directly affected by the events of September 11. Psychiatric Services. 2002; 53(11):1366-8. [PubMed: 12407258]

Michelozzi P, Capon A, Kirchmayer U, Forastiere F, Biggeri A, Barca A, Perucci CA. Adult and childhood leukemia near a high-power radio station in Rome, Italy. American Journal of Epidemiology. 2002; 155(12):1096-103. [PubMed: 12048223]

Mirabelli MC, Wing S, Marshall SW, Wilcosky TC. Asthma symptoms among adolescents who attend public schools that are located near confined swine feeding operations. Pediatrics. 2006; 118(1):e6675. [PubMed: 16818539]

O'Campo P. Invited commentary: Advancing theory and methods for multilevel models of residential neighborhoods and health. American Journal of Epidemiology. 2003; 157(1):9-13. [PubMed: 12505885]

Pickett KE, Pearl M. Multilevel analyses of neighbourhood socioeconomic context and health outcomes: a critical review. Journal of Epidemiology and Community Health. 2001; 55(2):111-22. [PubMed: 11154250]

TRD Team. R 2.2.1. 2006. p. 205

Richardson, S. Spatial models in epidemiological applications. Oxford University Press; 2003.

Richardson S, Abellan JJ, Best N. Bayesian spatio-temporal analysis of joint patterns of male and female lung cancer risks in Yorkshire (UK). Statistical Methods in Medical Research. 2006; 15(4):385-407. [PubMed: 16886738]

Rosenheck R, Fontana A. Use of mental health services by veterans with PTSD after the terrorist attacks of September 11. American Journal of Psychiatry. 2003a; 160(9):1684-90. [PubMed: 12944346]

Rosenheck RA, Fontana A. Post-september 11 admission symptoms and treatment response among veterans with posttraumatic stress disorder. Psychiatric Services. 2003b; 54(12):1610-7. [PubMed: 14645800]

Salsberry PJ, Chipps E, Kennedy C. Use of general medical services among Medicaid patients with severe and persistent mental illness. Psychiatric Services. 2005; 56(4):458-62. [PubMed: 15812097]

Sampson RJ, Raudenbush SW, Earls F. Neighborhoods and violent crime: a multilevel study of collective efficacy. Science. 1997; 277(5328):918-24. [PubMed: 9252316]

Sarkar U, Nascimento SF, Barbosa R, Martins R, Nuevo H, Kalafanos I, Grunstein I, Flannery B, Dias J, Riley LW, Reis MG, Ko AI. Population-based case-control investigation of risk factors for 
leptospirosis during an urban epidemic. American Journal of Tropical Medicine and Hygiene. 2002; 66(5):605-10. [PubMed: 12201599]

S. Institute. SAS 9.1.3. SAS Institute; 2006.

SAS. Calculating the distance between zip codes, 2006. SAS; 2006.

Satcher DS. Executive summary: a report of the Surgeon General on mental health. Public Health Reports. 2000; 115(1):89-101. [PubMed: 10968589]

Schwartz S. The fallacy of the ecological fallacy: the potential misuse of a concept and the consequences. American Journal of Public Health. 1994; 84(5):819-24. [PubMed: 8179055]

Susser E. Eco-epidemiology: thinking outside the black box. Epidemiology. 2004; 15(5):519-20. author reply 527-8. [PubMed: 15308946]

Thomas AJ, Eberly LE, Davey Smith G, Neaton JD. ZIP-code-based versus tract-based income measures as long-term risk-adjusted mortality predictors. American Journal of Epidemiology. 2006; 164(6): 586-90. [PubMed: 16893922]

Viel J, Arveux P, Baverel J, Cahn J. Soft-tissue sarcoma and non-Hodgkin's lymphoma clusters around a municipal solid waste incinerator with high dioxin emission levels. American Journal of Epidemiology. 2000; (152):13-19. [PubMed: 10901325]

Walkup JT, Boyer CA, Kellermann SL. Reliability of Medicaid claims files for use in psychiatric diagnoses and service delivery. Administration and Policy in Mental Health. 2000; 27(3):129-39. [PubMed: 10826215]

Waller L, Carlin B, Xia H, Gelfand A- Hierarchical Spatio-Temporal Mapping of Disease Rates. Journal of the American Statistical Association. 1997; 92(438):607-617.

Waller L, Turnbull B, Clark L, Nasca P. Chronic disease surveillance and testing of clustering of disease and exposure: Application to leukemia incidence and TCE-contaminated dumpsites in upstate New York. Environmetrics. 1992; (3):281-300.

Wang C. Invited commentary: beyond frequencies and coefficients--toward meaningful descriptions for life course epidemiology. American Journal of Epidemiology. 2006; 164(2):122-5. discussion 126-7. [PubMed: 16751259]

Weich S, Blanchard M, Prince M, Burton E, Erens B, Sproston K. Mental health and the built environment: cross-sectional survey of individual and contextual risk factors for depression. British Journal of Psychiatry. 2002; 180:428-33. [PubMed: 11983640] 
(a) 2000 data
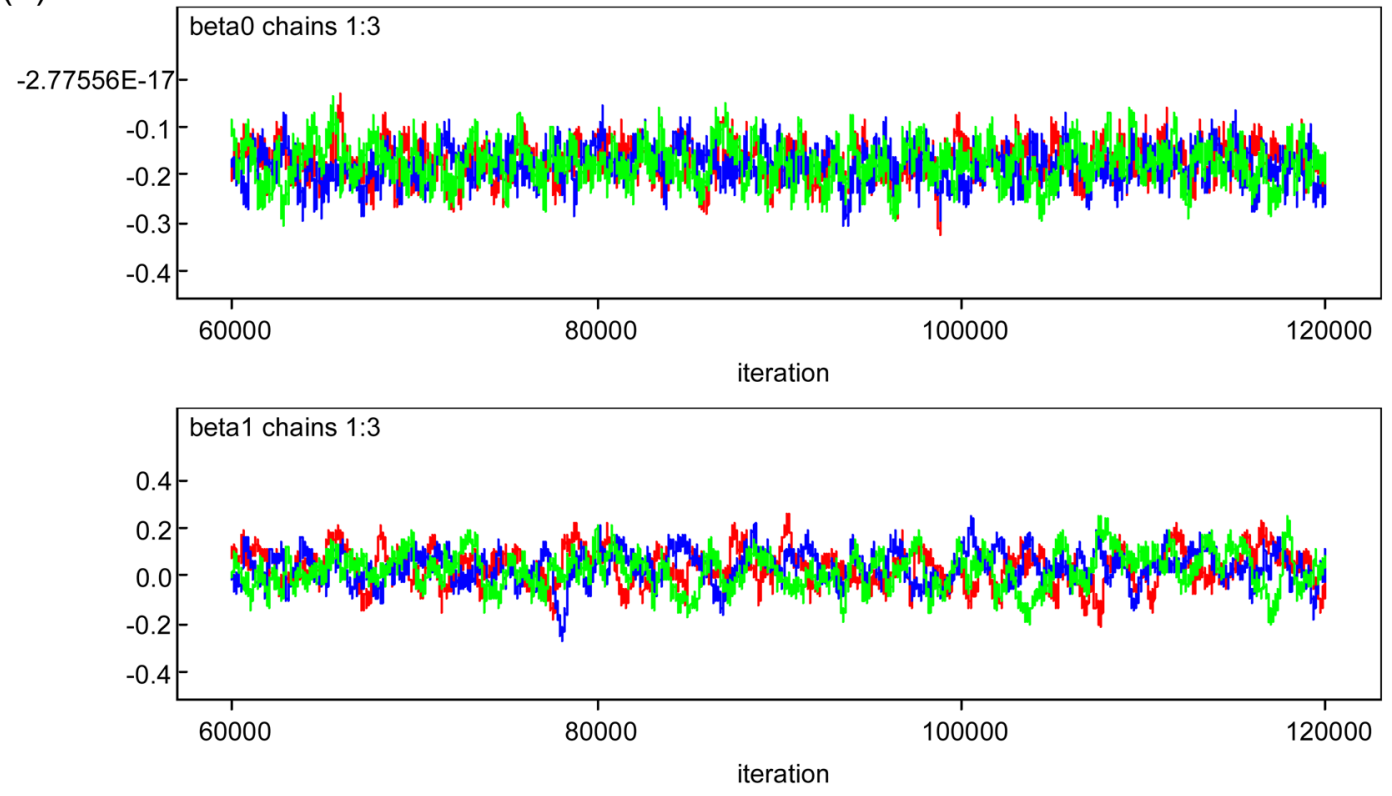

(b) 2001 data
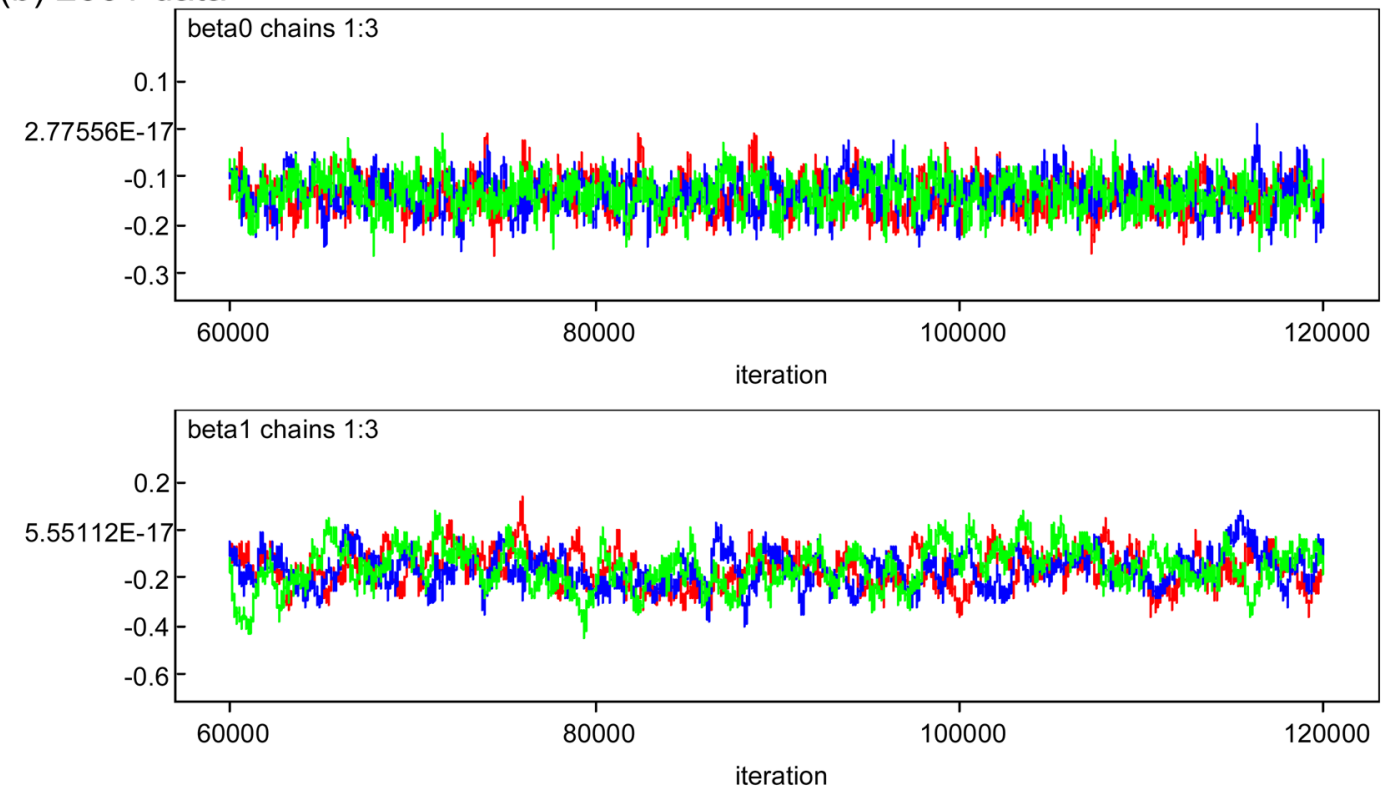

Figure 1.

Monte Carlo Markov Chain Convergence Tracings for $\beta_{0}$ and $\beta_{1}$ (a) 2000 data and (b) 2001 data. Post-September 11, anxiety-related outpatient diagnoses. New York City Medicaid Data. 


\section{(a) Distance from WTC $\left(\beta_{1}\right)$}

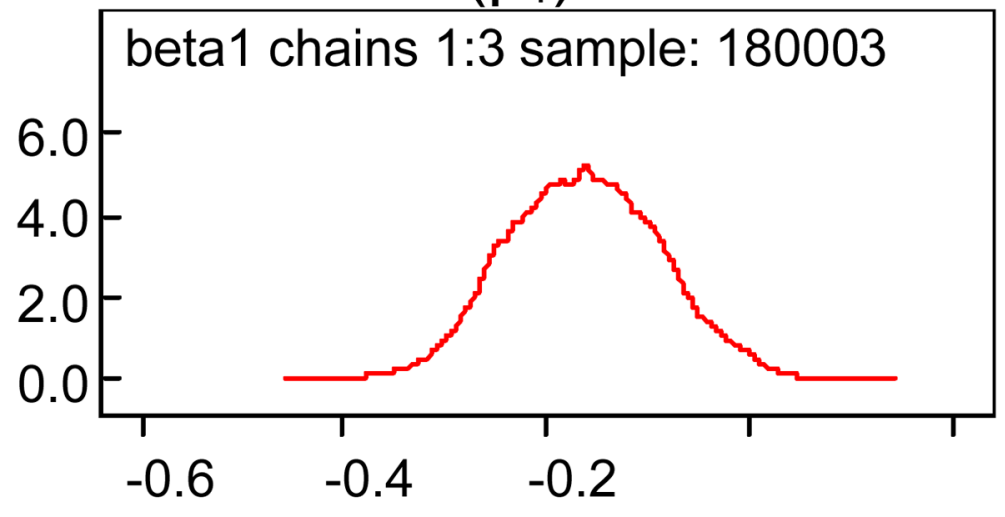

\section{(b) $9 / 11$ Deaths in Community $\left(\beta_{2}\right)$}

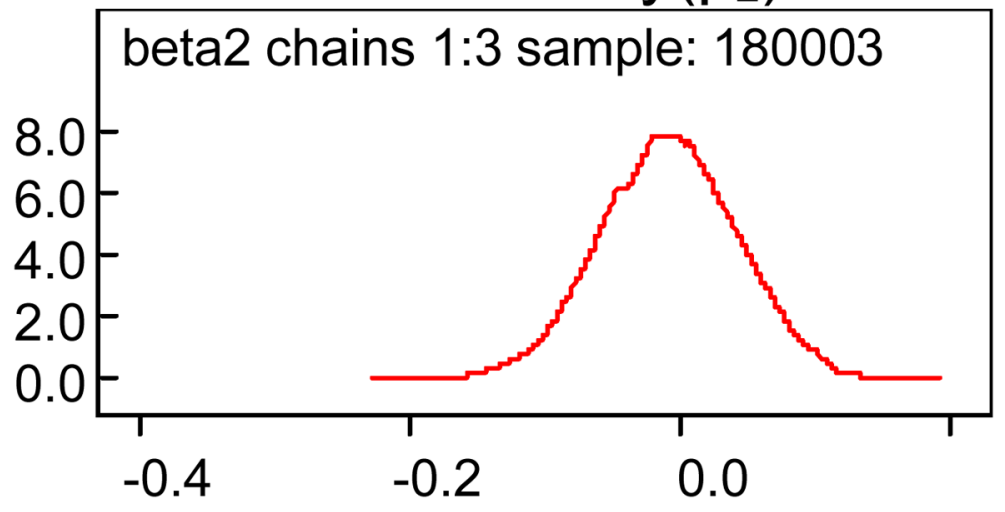

Figure 2.

Kernal density graphs of coefficients for (a) Distance from WTC $\left(\beta_{1}\right)$ and (b) $9 / 11$ Deaths in Community $\left(\beta_{2}\right)$ based on results of 60,000 iteration Markov chain Monte Carlo simulations. Post-September 11,2001 anxiety-related outpatient diagnoses. New York City Medicaid Data. 


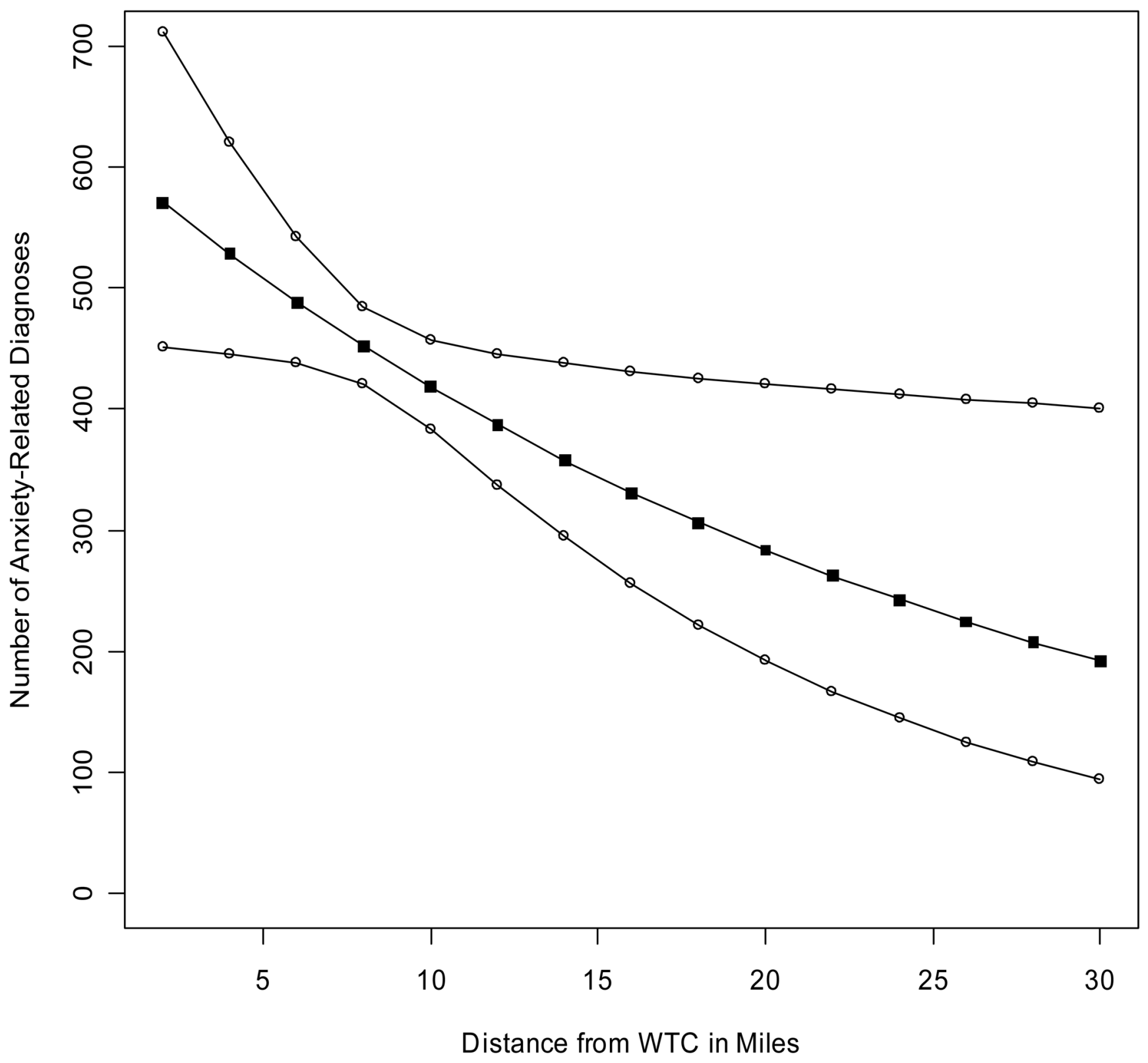

Figure 3.

Anxiety-Related diagnoses as a function of distance from the World Trade Center (WTC) site. Point estimates with upper and lower credible intervals for increasing number of miles from WTC holding other variables (age, gender, death rate in community, and median household income) constant. New York City outpatient Medicaid data, September 11 - December 31, 2001. 

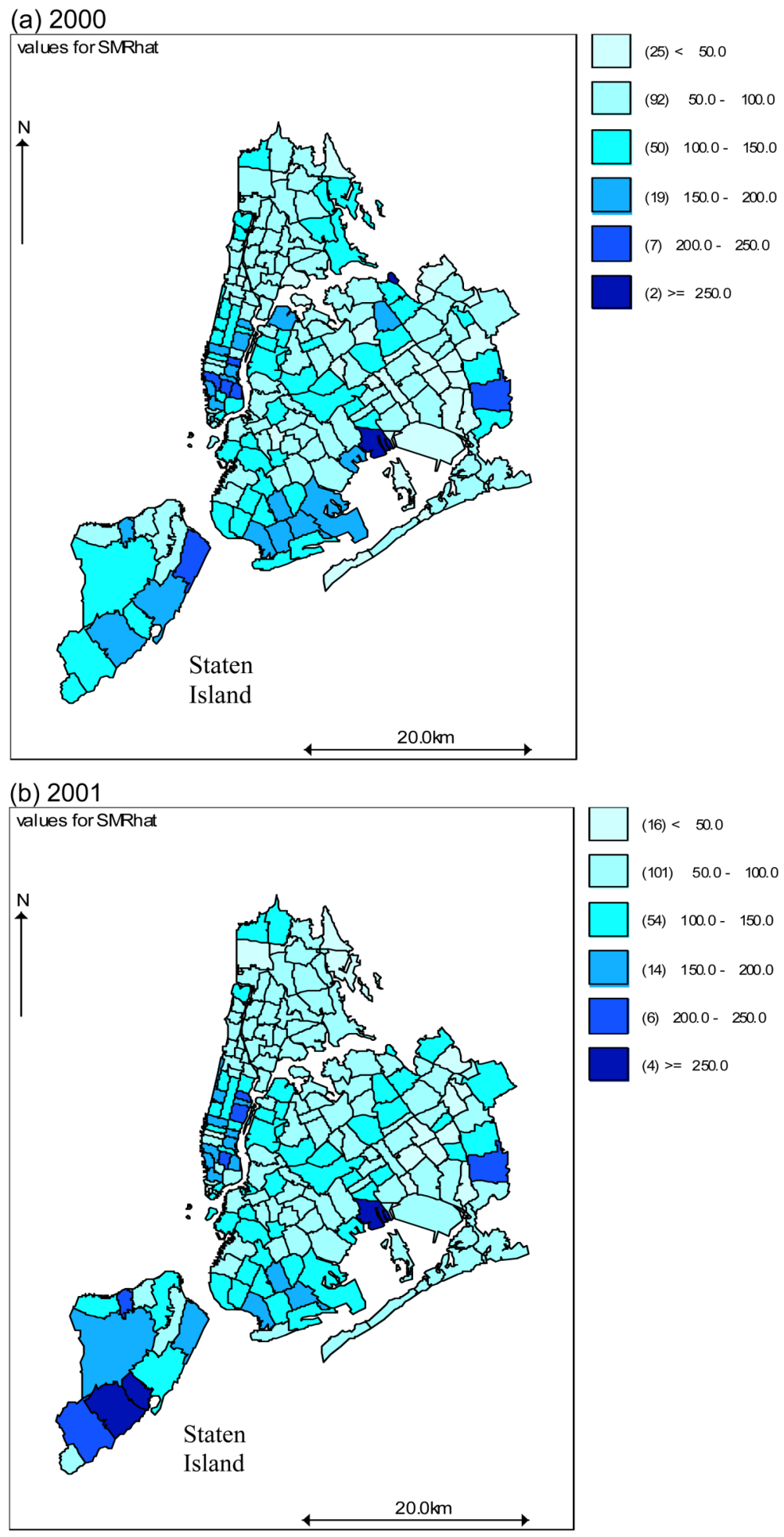

Figure 4.

Fitted Standardized Morbidity Ratios, Anxiety-Related diagnoses, New York City, September 11 - December 30 (a) 2000 and (b) 2001. New York City outpatient Medicaid Data. 


\section{Table 1}

Inference on coefficients for explanatory variables based on results of 60,000 iteration Markov chain Monte Carlo simulations. Post-September 11, anxiety-related outpatient diagnoses. New York City Medicaid Data.

\begin{tabular}{|l|l|l|l|}
\hline & node & median & 95\% CI \\
\hline \multirow{4}{*}{ Post-September 11, 2000 (Control Period) } & Intercept $\left(\beta_{0}\right)$ & -0.1774 & $(-0.253,-0.1042)$ \\
\cline { 2 - 4 } & Distance from WTC $\left(\beta_{1}\right)$ & 0.03049 & $(-0.1089,0.1643)$ \\
\cline { 2 - 4 } & $9 / 11$ Deaths in Community $\left(\beta_{2}\right)$ & 0.06984 & $(-0.02205,0.1649)$ \\
\cline { 2 - 4 } & Median Household Income $\left(\beta_{3}\right)$ & $7.68 \mathrm{E}-4$ & $(-0.1069,0.1083)$ \\
\hline \multirow{4}{*}{ Post-September 11, 2001 (Attack Period) } & Intercept $\left(\beta_{0}\right)$ & -0.1377 & $(-0.2023,-0.07)$ \\
\cline { 2 - 4 } & Distance from WTC $\left(\beta_{1}\right)$ & -0.1638 & $(-0.3045,-0.0143)$ \\
\cline { 2 - 4 } & $9 / 11$ Deaths in Community $\left(\beta_{2}\right)$ & -0.00738 & $(-0.1074,0.08598)$ \\
\cline { 2 - 5 } & Median Household Income $\left(\beta_{3}\right)$ & 0.05771 & $(-0.05244,0.1672)$ \\
\hline
\end{tabular}

